\title{
Reporting on the Financial Performance of Life Insurers
}

\author{
Jozef De Mey \\ Fortis, Rue Royale 20, Boulevard Emile Jacqmain 53 - 1JQ7A, Brussels BE-1000, Belgium.
}

The financial crisis has also affected the credibility of financial institutions' financial reporting. Life insurers, like other financial institutions, therefore, need to revamp their reporting to the investment community. The quality of reporting would benefit from explicit forward-looking statements, less emphasis on precision and more on ranges of possible outcomes and worst cases, and an increase in reporting frequency. Furthermore, internal and external financial reporting needs to be better aligned. Market-consistent fair value is defended as the preferred basis to measure assets, liabilities and earnings. As no single reporting view can provide a comprehensive picture, various views could be publicised. In addition to International Financial Reporting Standards fair value (phase II), Market-Consistent Embedded Value and Value of New Business, a third complementary view, labelled Source of Profit Analysis is proposed. This view is already used by many life insurance managers, and thus could help to better align external and internal reporting.

The Geneva Papers (2009) 34, 228 -241. doi:10.1057/gpp.2009.6

Keywords: life insurance; financial reporting; fair value measurement; MCEV

\section{Introduction}

The financial crisis of 2008 has profoundly changed the landscape of the financial sector, and has also led to a loss of credibility in the way it has been reporting on its profitability, risks and financial strength. Neither has the life insurance industry escaped this crisis. The primary focus of this paper will be on how the financial reporting of life insurers can be adjusted to the needs of the new reality, and in particular to the needs of shareholders and the investment community.

The first section of this paper describes briefly the information needs of the various stakeholders of a life insurance company. The second section focuses on the financial reporting needs of shareholders and the investment community. In the third section, various complementary financial reporting views aimed primarily at the investment community are discussed and evaluated. Finally, some concluding recommendations are given on how to improve the quality of financial information reported by life insurers.

\section{Reporting to various stakeholders}

Different stakeholders have different - financial and non-financial - information needs, and each must be properly served. Given its nature, the life insurance industry 
faces a more challenging task here than most other industries. Life insurance is relatively complex to understand - even for the economically literate - and it involves many different stakeholders, in addition to the shareholder.

\section{The other stakeholders}

- Supervisors focus on the solvency of the firm and on how fairly it treats its clients. Their perspective is preventive and increasingly forward-looking. Their primary interest is moving away from ex-post financial results towards making sure that the company has adequate internal control, risk management, compliance and governance systems in place. These stakeholders are, in terms of information, privileged in the sense that they have unlimited access to the company and can demand practically everything they want.

- Creditors have basically the same needs as supervisors, but they lack the full access that supervisors enjoy. They have to rely on the view of rating agencies, which often do have some access to non-public company information.

- For employees, information should not only be about the financial performance of the firm, but should also include items such as size and composition of the workforce, absenteeism, turnover rates, motivation surveys, etc. Most of this information is typically included in a Social Annual Report. The contribution to society is also an item of increasing interest for employees.

- Distributors want to know whether they can count on a long-term partner that is reliable and competent. Like creditors, their main interest is to know whether their insurance partner is financially strong.

- Clients and potential clients want to be assured of the capacity of the company to fulfil its long-term obligations, and that it is offering attractive prices and/or returns with adequate service.

- The general public basically demands to know whether insurance companies are behaving like efficient corporate citizens.

- The media can be considered a special stakeholder. It is a disseminator of information that significantly influences the perception of the other stakeholders. It is often even the main - or only - source of information that is used by the general public and many customers and distributors. Some media sources will be more knowledgeable than others, but they will all tend to amplify what is "exceptional" and will tend to ignore "business as usual" news. They want quick and simple messages.

The main need of all the aforementioned stakeholders is to know the long-term financial strength of the company and whether it behaves like an efficient corporate citizen. As in the current financial world, the importance of these stakeholders has increased, and more emphasis should indeed be given to the information they require.

Two other important stakeholders are missing from the list above: the managers and the shareholders of the company. Their information needs and how these needs are interrelated deserve special treatment. 


\section{Management}

It may seem strange to list management as an information user, as it is the company's management that does most of the reporting. It is, however, important to include managers here, not only because they receive and use a great deal of (management) information but also because consistency between the external and the internal reporting is essential in aligning the actions of management with the demands of the external world. Should the internal systems that are used to manage the business be inconsistent with how the company informs the external world, and in particular the investment community, then the long-term continuity of the company (and its management) would be at risk. Therefore, ideally, the information to the external world should be a reflection of how management looks at the business.

For internal performance management purposes, management needs to measure the performance against a reference point or target. This can be an ex-ante objective (the budget) or an external benchmark.

\section{Shareholders}

Shareholders, and the investment community at large, are the primary users of financial reports. How their needs could be better addressed will be the essence of the rest of this contribution.

Much progress has been made on the various forms of information for the other stakeholders. Companies produce Corporate Social Responsibility Reports, Social Annual Accounts, etc., which are increasing in frequency, size and content. This type of information is also increasingly relevant for shareholders, and the essentially financial, earnings-driven view is losing some of its supremacy.

Currently, it is actually the quality of the financial reporting to shareholders and the investment community - the traditional "core" of the reporting function - that is being questioned. This will be the main subject of the next section. But first the basic criteria that have to be met by any type of reporting will be described, with an emphasis on the needs of shareholders and the investment community.

\section{Information quality criteria}

An adequate reporting system must provide information that meets three basic quality criteria. Information should be comprehensive, timely and reliable. ${ }^{1}$

\section{Comprehensive}

The information provided should be relevant and should cover all the important aspects of the business. A consolidated net profit figure together with some general

${ }^{1}$ This classification varies more in form than in content from other well-known, generally accepted classifications provided by, for example, the IASB or FASB. For instance, "timely" is normally considered an aspect of relevance. 
statements on how the company has performed may be comprehensive enough for the media and the general public. But the investor community expects something more. It wants detailed ex-post numbers and ex-ante information that is consistent with internal management information.

The ex-post information should cover all the key performance criteria and should be sufficiently granular and transparent. The numbers should also be presented in a multi-dimensional fashion, showing the performance of all the relevant segments.

The investment community also expects from management some kind of ex-ante information. It needs this as a basis for its expectations about the future performance of the company. Although many managers and company boards are reluctant to provide any forward-looking statements - even with a clear disclaimer - the fact is that the investment community needs such a prospective managerial view. One can even argue that this is more relevant than ex-post performance reporting. If management does not wish to provide any indication about the future, then the financial analysts community will. But their opinion will then be based on their own, probably more limited, views.

The arguments against providing prospective information are well known: it could be a source of surprise (thus volatility) if created expectations are not met, and it could provide competitors with an additional insight into the strategy of the company, supposedly giving them an advantage, if they do not themselves give such projections. With respect to the first argument, we could claim the precise opposite. Expectations formulated by financial analysts can also be missed, and this is even more probable, as financial analysts lack the details and context that management has to provide an indication for the future. ${ }^{2}$ The second argument is more a reflection of a naïve underestimation of what a smart competitor could find out itself about the strategy of the company. Add to this the extra risk premium that the investment community will apply for being left "in the dark" and the conclusion should be that providing forward-looking statements makes sense.

But such prospective information should not be just a set of ambitious "hard and precise targets", but more a set of best estimates within a range of possible results supported with sensitivities to a few basic scenarios. It should not only be about the strategic direction of the company but should also include statements about the risk tolerance of the company (in terms of earnings and value at risk, for example) that the proposed strategy implies. Disclosures about risk management in financial statements typically include ex-post quantitative sensitivities to various types of risk, but the link to the company's strategy and a view on what is an acceptable level of sensitivity are typically still lacking.

Comparability and consistency are second-order qualities of relevance that financial information should possess, particularly in the eyes of the investment community. Consistency over time for one enterprise should indeed be feasible. But given the high degree of heterogeneity within the life insurance industry, not to mention between life insurance and other industries, real relevant comparability might never be achieved.

\footnotetext{
${ }^{2}$ This is a statement similar to the arguments put forward in the Agency and Asymmetric information theory; see for example Ross (1973).
} 


\section{Timely}

"Timely" is obviously not several months after the end of the reporting period, as is often the case with the annual financial statements. The relevance of information diminishes, as the period to which it refers lies more in the past. Financial information is perishable, and very quickly passes its "use-by" date.

A second related dimension of timeliness is the frequency of reporting. It is of limited value to the investment community to receive the full annual figures immediately after the end of the year but then have to wait another 12 months for the next report. Given an increased uncertainty - and observed market volatility - it is stating the obvious that the frequency with which life insurers should report to the outside world should increase. A higher information frequency would reduce the information asymmetry between management and the investor community and related moral hazard uncertainty. ${ }^{3}$

For the investor community, the ideal would be to have all relevant information immediately each time something relevant is known. The industry has been working hard on a faster closing of annual and quarterly results, but has neglected the frequency dimension.

\section{Reliable}

The reliability of information is the degree to which it verifiably corresponds with reality. Much of the debate about the quality of financial information concerns this aspect. The debate is both about the correct way to measure financial results and about how reliable this measurement is. When we speak about the correct way to measure financial results, we are entering the discussion about accounting standards. In the next section, we will strongly argue in favour of "fair value" measurement. When we deal with reliability, we are referring to the quality of internal controls and the role of accountants and actuaries in verifying information.

"Reliable" is not the same as "precise". We should be aware of the false sense of certainty that a precise financial number can give. Unfortunately, much effort seems to be wasted in trying to achieve an illusion of precision. A range of possible outcomes can be far more relevant than a best estimate, however precisely this is calculated. Put in another way, the worst-case scenario is far more consequential than the best estimate. Thus, much more effort should be spent on providing reliable ranges of possible outcomes, which in fact has more to do with comprehensiveness than with reliability.

In addition to these basic criteria, information must also be presented in a format and language that are understandable to its recipients, and obviously the value of this information should be higher than the cost of producing it.

It is evident that all these criteria cannot be evaluated separately, as they are strongly related. For example, speed and high frequency do not mix well with

\footnotetext{
${ }^{3}$ This solution to the moral hazard problem is part of the signalling theory first developed by Spence (1974).
} 
reliability and granularity. An increasingly difficult balance must be found between these criteria, as the expectations of stakeholders are also a moving target. They, and in particular the investor community, have an insatiable thirst for more relevant and forward-looking information provided faster and above all more often.

\section{Financial reporting standards and principles}

It is far beyond the scope of this paper to discuss at a sufficiently detailed level the relative merits and drawbacks of the various accounting principles and approaches that can be applied in the financial reports of the life insurance industry. ${ }^{4}$ The two most popular approaches will be briefly analysed: the accounting and the embedded value approach. In terms of measurement, both of these are gravitating towards "market-consistent fair value", a principle that - undeservingly - is often criticised. A third complementary reporting perspective will be suggested that could help to bridge the widening gap between how management looks at its business and how the financial results are represented to the external world.

\section{Accounting-based reporting}

We can distinguish between financial accounting based on International Financial Reporting Standards (IFRS) and reporting based on local statutory Generally Accepted Accounting Principles (GAAP).

Local GAAP: All life insurers have to produce financial statements based on their local GAAP. Supervisory authorities require these, and tax authorities also use local GAAP, with adjustments, to establish the taxable base. These accounts are also typically the basis on which profit-sharing rules are based, which makes them very relevant for with-profit life insurance business.

Local GAAP tends to be accrual accounting-based, with often only minor consideration for market values, although there is a trend towards IFRS. With some exceptions, these accounting principles are by nature "rules-based" rather than "principle-based". Due to their low frequency, late publication and their rigid nature, both in terms of form and content, these accounts do not provide the primary view to management or the investment community. But nevertheless they cannot be ignored given their impact on tax and profit sharing.

IFRS: The current standard IFRS 4 Insurance Contracts, often referred to as Insurance IFRS phase I, is an interim standard to measure insurance contracts (liabilities), and still allows a variety of practices. The ultimate phase II standard is expected to be introduced by 2011, and should bring "fair value" measurement - more on this will be discussed later in the paper. Currently, a public consultation is in progress that will have to lead to an Exposure draft by 2010 . The already published

\footnotetext{
${ }^{4}$ Dickinson (2003).
} 
Discussion Paper $^{5}$ proposes that an insurer should measure its liabilities using three "building blocks":

- explicit "market-consistent" estimates of future contractual cash flows;

- use of current market discount rates to determine the present value of cash flows;

- an explicit and unbiased estimate of the margin that market participants require for bearing risks associated with the liability (a "risk margin") and for providing other services, if any (a "service margin").

The name for this measurement that has been put forward by the International Accounting Standards Board (IASB) is - strangely - not fair value, but "current exit value'.

Many key issues of IFRS phase II are still unclear, in particular on how to reconcile the concepts of market consistency and estimated risk margins. Which discount rate to apply is also a source of debate. But the general direction seems to be towards a "docile" version of fair-value measurement of liabilities with room for subjective judgements.

For performance management purposes, an absolute IFRS earnings number is not very relevant. It needs to be accompanied by a target, and/or to be combined with a required (risk) capital number to arrive at a return on (risk adjusted) capital. Such types of ratios are by now well known and are a powerful performance management concept, although not without drawbacks, particularly when used in isolation.

The strengths of this approach are the level of granularity in IFRS accounts and disclosures, the comparability of the outcomes and (when IFRS phase II is applied) its intention to reflect economic reality. The drawbacks are its low frequency, late publication and a limited connection to the way managers actually look at their business.

\section{Embedded value-based reporting}

In contrast to traditional accounting measures, the embedded value approach developed by the life insurance industry reflects the value of expected future distributable profits "embedded" in the portfolio of in-force business. In addition to this Value of In-Force Business (VIF), most life insurers also disclose the value added by last year's new sales, more often labelled as Value of New Business (VNB). The sum of the VIF and VNB plus capital represent the total value, sometimes referred to as the Appraisal Value, of the life insurance business.

With the publication of the European Embedded Value (EEV) Principles ${ }^{6}$ by the Chief Financial Officers' (CFOs) Forum, a standard set of principles for the calculation of embedded values was established. This allowed for more consistency and comparability across the industry. But a proper and consistent allowance for risks - clearly a key issue for the performance evaluation of a life insurer - was still missing. In response to this criticism, the industry has developed a new set of principles to

\footnotetext{
${ }^{5}$ IASB (2007).

${ }^{6}$ CFO Forum (2004).
} 
calculate Market-Consistent Embedded Value (MCEV). ${ }^{7}$ The subjective concept of a risk discount rate used in the previous embedded value approaches is in MCEV to be removed by valuing assets and liabilities in line with market prices and consistent with each other. This is in essence the market consistency principle.

The MCEV of the in-force business consists of

- The present value of future after tax profit (PVFP), which should also include the intrinsic value of any (embedded) financial options and guarantees.

- The time value of financial options and guarantees.

- The frictional costs caused by holding a required capital, which essentially reflects the effect of double taxation.

- The cost of "non-hedgeable" risks not already included in the PVFP or in the time value of financial options and guarantees.

The disclosure proposed in the MCEV principles includes many key elements of the calculations and very useful additional information. In particular, the sensitivity analysis of the value and the breakdown of the MCEV earnings in a prescribed template enhance the quality and comparability of the approach.

Although MCEV is certainly a very important step forward in financial reporting for life insurers, some issues remain:

- Options and guarantees embedded in the liabilities are to be valued using standard option-pricing models or stochastic simulation, which seems feasible if we assume that policyholders are 100 per cent rational, "efficient" investors. But they are not. Policyholder behaviour is dynamic across stochastic scenarios and is difficult to model, thus requiring judgement. The CFO Forum seems to give the impression that this dynamic behaviour would not be material: "Dynamic behaviour should, where material, be in the allowance for time value of financial options and guarantees". ${ }^{8}$ But it might seriously underestimate the impact, as introducing only a minor degree of dynamic policy behaviour can increase the cost of the financial options by more than 130 per cent. ${ }^{9}$

- In a survey conducted in 2006 by Watson $\mathrm{Wyatt}^{10}$ on the challenges faced by the life insurance sector in adopting MCEV, the cost of non-hedgeable risks was mentioned by more than 60 per cent as the main area for improvement. The market consistency principle introduced by the MCEV aimed to eliminate the nebulous effect of the risk discount rate. But the strength of the MCEV approach might be weakened by the introduction of an equally fuzzy and subjective "allowance for non-hedgeable risks".

In the already mentioned survey by Watson Wyatt, some relevant points emerged with respect to the use of MCEV for performance management and reporting purposes:

- The most popular measure for performance management for 50 per cent of the participants was IFRS earnings. MCEV and VNB were each considered the most

\footnotetext{
${ }^{7}$ CFO Forum (2008).

${ }^{8}$ CFO Forum (2008).

${ }^{9}$ Kent and Logan (2008).

${ }^{10}$ Watson Wyatt (2008).
} 
important measure by slightly more than 20 per cent. When evaluating product profitability, VNB was considered the key measure by 66 per cent of the respondents.

- Surprisingly, only 32 per cent of respondents expected the new MCEV principles to satisfy the investment community. Clearly, the sector believes that investors expect more.

The strong points of MCEV are its market consistency and consideration of risks within a framework that allows reasonable comparability. The major handicap is its low frequency and limited link to how the business is really managed. This does not mean that it is not a very powerful management tool, but it is not the main system for management information.

Independent of their place in the MCEV framework, the VNB calculations bring something extra. They provide a forward-looking view on value creation. The VNB can be calculated faster (thus with a higher frequency) than the full MCEV, but there is still a lot of room for judgement in the calculation, making comparability still difficult.

\section{Convergence on the horizon?}

A desire expressed by the insurance industry that can be deduced from many of the comments on the IFRS phase II Discussion Paper is for IFRS and MCEV standards to eventually converge, and to also apply similar measurement principles in the new European Union (EU) solvency framework under construction, known as Solvency II. Although the aforementioned survey by Watson Wyatt showed pessimism among its respondents about the chances that MCEV and IFRS phase II would converge, the approaches have many key aspects in common. The way that assets are to be valued is in principle the same, being essentially market prices when these are available, whereas the measurement of liabilities in both cases is to be "market-consistent" although this concept is differently defined. Both approaches propose to calculate present values of future liability cash flows without using a risk-adjusted discount rate, but including a sort of "margin". In IFRS, the terms "risk margin" and "service margin" are used, whereas MCEV uses the allowance for "non-hedgeable" risks.

What standard setters and the industry actually want to accomplish with these margins and adjustments is to allow for profits to emerge only gradually, as these margins and allowances are gradually "earned" over time. This prevents any meaningful profit at inception from emerging, which is the main bridge on the road to truly market-consistent fair value that standard setters and the industry are still hesitant to cross. But do shareholders and the investment community share this aversion to profit at inception?

Clearly, the stickiness of conservative accrual accounting thinking and the desire to show smoothly growing results are deeply rooted. This could affect the way in which both IFRS phase II and MCEV are evolving. Both might eventually converge somewhere along the road, but the possibility exists that the IFRS phase II project will choose a different road than MCEV and allow much more judgemental considerations. The IFRS phase II project runs the real risk that market-consistent fair value will eventually be represented in name only. 
Fair value: Friend or foe

Value, like beauty, lies in the eye of the beholder.

The concept of fair value in financial reporting has been very much centre stage in recent debates. Some have started to question the validity of mark-to-market accounting for certain assets, as a result of the financial turmoil during the year 2008 . It has even been suggested that it is this principle that has aggravated the financial crisis triggered by the sub-prime credit market.

Some of this criticism might be justified, and applying fair value to measure life insurance liabilities might indeed be even more challenging. If problems due to illiquidity and absence of a truly liquid and deep market was such an issue to put a reliable market-consistent value on certain assets (such as Collateralised Debt Obligations, for example), what about the hopes of getting to unbiased marketconsistent fair values on the practically totally illiquid liability side of a life insurer? As can be deducted from the issues that surfaced when commenting on IFRS phase II and MCEV, this is indeed a challenge.

But there is nothing intrinsically wrong with reporting an asset or liability at its "fair price". The obvious question is whether the last known price is the fair price. Typically, we think about cases where the market is - or seems to be underestimating the fair price, as many market participants are in a "forced" selling mode. But there are also striking examples of the opposite. Take the case of Volkswagen during the last weeks of October 2008, when it briefly became the world's most valuable company by market capitalisation. ${ }^{11}$

Furthermore, the IASB recognised such problems in their announcement of 14 October $2008^{12}$ and allowed a more flexible approach: “... the objective of a fair value measurement is the price at which an orderly transaction would take place between market participants on the measurement date, not the price that would be achieved in a forced liquidation or distress sale". And further in their press release, "...that using the entity's own assumptions about future cash flows and appropriately risk-adjusted discount rates is acceptable when relevant observable inputs are not available". But determining what a "distressed sale" is or when "relevant observable inputs are not available" requires subjective judgement, which seriously reduces the relevancy of the fair value measurement applied in such cases.

The real problem is not fair value measurement, but it is the way it impacts available capital - or solvency in the case of insurers. It is the sudden and fierce change in available solvency caused by a rigid use of fair value measurement in determining available and required solvency that is at the root of the self-enforcing downward spiral of decreasing prices triggering forced sales leading to even lower prices. If solvency rules were based on a more pragmatic and contingent - but not less prudent - framework, then much of the criticism on fair value reporting would disappear.

\footnotetext{
${ }^{11}$ The surge in value of Volkswagen was triggered by a "squeeze" on short-sellers as Porsche revealed a much higher stake in Volkswagen than the market thought it had. As it became known that German regional governments and Porsche owned close to 95 per cent of the stock, leaving a free float of just 5 per cent, short-sellers ran for the exit and the price (fair value?) went through the roof.

12 IASB (2008).
} 
Such a pragmatic solvency approach could be perfectly consistent with the EU Solvency II framework ${ }^{13}$ and with fair value measurement. Much more emphasis should then be placed on the second pillar (risk management and supervisory requirements) and third pillar requirements (reporting and disclosure). With respect to the first pillar, the quantitative requirements, the Minimum Capital Requirement should very probably be set at a higher level than currently envisioned to allow for the increased volatility we have witnessed in financial markets. The level for Solvency Capital Requirement, although, could be made contingent on the economic cycle, and thus could be set at a higher level when assets increase in value, and could be relaxed, as the economic cycle leads to lower asset values. ${ }^{14}$ This would serve as a countercyclical mechanism that could prevent downward spirals or overaggressive expansion, and would still allow measurement of assets and liabilities at market-consistent fair value.

Again, there is nothing fundamentally wrong with measuring and reporting on a mark-to-market fair value basis, provided this information is used with care, for the right purpose and complemented with other measurement criteria and views. And, in particular, it should be complemented with a view that matches how management looks at and manages its business.

\section{A managerial view: Source of Profit Analysis}

While the accounting and to some extent also the embedded value approach tell us what happened during a period and give us a snapshot view of the (fair) value of the company, they typically reveal little on why the results are as shown. One should also not ignore the fact that fair value-based reporting is definitely not (yet) fully embraced by managers of life insurance companies as their main managerial reporting view.

An analysis of the sources of profit ${ }^{15}$ is a simple way to deconstruct the activity of a life insurer that provides some answers to the why question. Such an analysis is already being demanded by many supervisors, but unfortunately it is often not in the public domain. ${ }^{16}$ It is also a view on the business that is used internally by many life insurers, and some are starting to make these analyses public. ${ }^{17}$

A source of profit analysis sheds light on the performance of the key activities of a life insurer, and consists basically in a split of profit into three main sources: ${ }^{18}$

- The risk margin is the margin between premiums earned for risk covers such as death or disability and the related incurred claims. It reflects how good the company is in underwriting, pricing and managing, in essence, biometrical risks.

${ }^{13}$ Commission of the European Communities (2008).

${ }^{14}$ A similar approach is still successfully applied by the Spanish Central Bank in their supervision of Spanish banks.

${ }^{15}$ Sometimes called an "organic Profit \& Loss statement".

16 The Dutch DNB being one of the exceptions.

${ }^{17}$ For example, ING showed such an analysis in their analyst presentation for the first quarter of 2008.

18 There are also other, normally minor, sources of profit such as surrender margins and reinsurance margins. In addition, the terminology used differs by country. The Dutch Central bank, De Nederlandsche Bank, being one of the exceptions, uses the terms profit or loss in technical analysis (read risk), interest (read investments) and expenses. 
- The expense margin reflects as revenue the cost loadings and fee income received minus the operating costs and commissions paid, plus, if applicable, capitalised acquisition expenses minus amortisation of these expenses. It reveals a great deal about the efficiency of the company in its broadest sense, thus also including its commercial activity. Furthermore, a positive expense margin is a signal that the profitability of a life insurer does not depend on an uncertain risk margin and volatile investment margin.

- The investment margin is the spread between investment income and interest credited to policyholders, including profit sharing. Sometimes unrealised capital gains or losses are included in the investment income; sometimes they are shown separately. This investment margin could also be calculated on an MCEV basis, and given its financial nature it should not have to be "polluted" by the highly subjective allowance for non-hedgeable risks applied in the MCEV. Typically, the investment margin has been the main source of profit (or loss) for most life insurers, and it reflects, in essence, how the company's asset liability management performs.

This information is particularly relevant when split by relevant geography, product segment or distribution channel. As already stated, its main strengths are the link to the way in which managers manage their business and the possibility to frequently report this information. The price to pay for high frequency and relevance is limited accuracy and comparability.

Such information, complemented with an indicative VNB and ranges of marketconsistent values for the main items in the balance sheet of a life insurer, could be provided at least monthly. This would considerably improve the comprehensiveness and frequency aspects of the financial information provided.

\section{The futile search for the reporting holy grail?}

Ultimately, the investor community wants the long-term value creation capacity of a company to emerge from its financial reporting. But how to unambiguously measure this in a comprehensive, reliable and timely way, properly considering all the associated risks? And how to communicate this is in a way that is transparent and understood?

Maybe we just have to accept that there is no - or at least not yet - unique approach, although fair value-inspired solutions go a long way. The complexity of the life insurance business requires the use of different systems and principles simultaneously, each providing their own perspective. Looking at each measure in isolation is not meaningful, but by putting them together, a picture resembling a true "fair" view could be drawn. Table 1 shows a simplified summary of the way in which each of the financial reporting views that have been discussed above contributes to providing such a fair view.

\section{Concluding remarks}

Exceptional times require exceptional measures. Changes in the way the life insurance industry presents its performance could be one of these exceptional measures, as the 
Table 1 How do the different reporting views meet information quality criteria?

\begin{tabular}{|c|c|c|c|}
\hline & $\begin{array}{l}\text { Accounting IFRS phase II } \\
\text { view }\end{array}$ & $M C E V+V N B$ & $\begin{array}{l}\text { Profit source analysis }+ \text { key } \\
\text { ratios and values }\end{array}$ \\
\hline Comprehensive & $\begin{array}{ll}\text { - High level of } \\
\text { granularity } \\
\text { (Maybe) market } \\
\text { consistent (in IFRS } \\
\text { phase II?) } \\
\text { Risks are disclosed } \\
\text { but not explicitly } \\
\text { valued } \\
\odot \odot)\end{array}$ & $\begin{array}{l}\text { Market-consistent } \\
\text { view accounts } \\
\text { explicitly for } \\
\text { (financial) risks } \\
\text { Reflection of value } \\
\text { creation capacity } \\
\text { Limited (obligatory) } \\
\text { granularity } \\
\odot \odot\end{array}$ & $\begin{array}{l}\text { - Linked to management } \\
\text { view } \\
\text { - Insight into why value } \\
\text { is created } \\
\text { - Can be market } \\
\text { consistent }\end{array}$ \\
\hline Comparability & $\begin{array}{l}\text { High, certainly under IFRS } \\
\text { phase II } \\
\odot \odot \odot \odot \odot\end{array}$ & $\begin{array}{l}\text { Increasingly comparable } \\
\odot \odot \odot\end{array}$ & $\begin{array}{l}\text { Certainly not yet } \\
\odot\end{array}$ \\
\hline Timely & $\begin{array}{l}\text { Full financial statements } \\
\text { are too late and too } \\
\text { infrequent } \\
\odot\end{array}$ & $\begin{array}{l}\text { Typically late and } \\
\text { infrequent } \\
\text { (once a year) } \\
\text { ()) }\end{array}$ & $\begin{array}{l}\text { Quicker and more } \\
\text { frequently available } \\
\text { than other reports } \\
\text { (-) })\end{array}$ \\
\hline Reliable & $\begin{array}{l}\text { In principle, the most } \\
\text { reliable of all approaches } \\
+()-\end{array}$ & $\begin{array}{l}\text { Some judgement } \\
\text { required }\end{array}$ & $\begin{array}{l}\text { Can be as reliable as } \\
\text { financial accounts, but } \\
\text { speed would then suffer } \\
(-))\end{array}$ \\
\hline
\end{tabular}

traditional ways have failed to project a true, fair and updated view of the value and value-creating capacity of life insurers.

To summarise, the main messages and concerns included in this paper are as follows:

- Different stakeholders have different needs. The supremacy of the shareholder might have become less dominant, but his needs remain the primary concern to be addressed in financial reporting, and actually it is in this area where the need for improvement is the most urgent.

- The management of life insurance companies should dare to add explicit forwardlooking statements not only about strategic objectives and long-term financial targets, but also about its risk appetite and possible worst-case scenarios.

- Volatility and uncertainty have reached new heights. This requires more frequent and faster available information, so as to reduce the information asymmetry between management and shareholders and its related uncertainty.

- There is a difficult trade-off to be made between several quality criteria that financial information must meet. Less energy should be expended in getting to "precise and exact" numbers, and more attention should go to possible ranges of outcomes - in particular the so-called worst cases. That is relevance over reliability. Both the industry and the investment community need to accept that there is a 
degree of judgement involved in all measurements, and that the future impact of risks cannot be precisely known.

- Ultimately, economic value added is the principle measure of financial performance. But today, there is no real unanimous opinion on the right way to do this. The simultaneous use of various complementary well-disclosed approaches and views (IFRS phase II fair value, MCEV and a managerial view such as Profit Source Analysis) and maintaining measurement close to mark-to-market or market-consistent fair values seems as far as we can get today.

\section{References}

CFO Forum (May 2004) 'European Embedded Value Principles', www.cfoforum.nl

CFO Forum (June 2008) 'Market Consistent Embedded Value Principles', www.cfoforum.nl

Commission of the European Communities (2008) 'Amended Proposal Solvency II', COM (2008) 119, February 2008.

Dickinson, G. (2003) 'The search for an international accounting standard for insurance: Report to the accountancy task force of the Geneva association', The Geneva Papers on Risk and Insurance - Issues and Practice 28(2): 151-176.

IASB (2007) Discussion paper: Preliminary views on insurance contracts, IASB, May 2007.

ING (2008) 'Presentation on Quarterly Results', www.ing.com/group/showdoc.jsp?docid = 321046_ EN\&menopt $=$ ivr $|\operatorname{apr}| q p r \mid 008$.

International Accounting Standards Board (2008) Press Release "IASB Provides Update on Applying Fair Value in Inactive Markets". 14 October 2008, www.iasb.org/News/Press + Releases/IASB + provides + update + on + applying + fair + value + in + inactive + markets.htm.

Kent, J. and Logan, E. (2008) 'Dynamic Policy Behaviour', paper presented to the Staple Inn Actuarial Society, November 2008.

Ross, S. (1973) 'The economic theory of agency: The principal's problem', American Economic Review 63(2): 134-139.

Spence, M. (1974) Market Signalling: Information Transfer in Hiring and Related Screening Processes, Harvard University Press.

Watson Wyatt (2008) 'MCEV Principles: The Industry View', September 2008.

\section{About the Author}

Jozef De Mey graduated as an actuary from the University of Leuven, after graduating in Mathematical Sciences. Before joining Fortis, he was Chairman of John Hancock International Services. Between 1990 and 1995, he was CEO of Fortis International and from 1995 to 2006, he was CFO of Fortis Insurance Belgium. He was a member of Fortis Executive Committee from 2000 to 2007. Since February 2009 he is Chairman of the Board of Fortis Holding. 